\title{
The effects of tutorial class for female students on their academic achievement in Wachemo University, Ethiopia
}

\author{
Sewagegn Mola Melaku*, Wachemo University, Department of Social Psychology, Hosaena, Ethiopia
}

\section{Suggested Citation:}

Melaku, M. S. (2021). The effects of tutorial class for female students on their academic achievement in Wachemo University, Ethiopia. Global Journal of Guidance and Counseling in Schools: Current Perspectives, 11(2), 66-76. https://doi.org/10.18844/gigc.v11i2.5276

Received March 1, 2021; revised May 29, 2021; accepted July 11, 2021.

Selection and peer review under responsibility of Prof. Dr. Kobus Maree, University of Pretoria South Africa. (C)2021 Birlesik Dunya Yenilik Arastirma ve Yayincilik Merkezi. All rights reserved.

\begin{abstract}
The purpose of this study was to assess the effectiveness of tutorial class on female students' academic achievement in Wachemo University. The study employed the experimental research design. Data were collected from 10\% (60) of the female students as a sample from the total of 598 female students by using simple random sampling techniques and 11 teachers out of 114 teachers were selected by using purposive sampling techniques. The results revealed that tutorial support has both academic and psychological effects on female students. Academically, tutorial class is effective in improving a student's academic performance. Psychologically, tutorial support is effective in improving their self-confidence, selfconcept, decision-making ability, memory and feeling of happiness. Finally, the study suggested that tutorials are indispensable factors in the achievements of educational goals and objectives. Therefore, students, teachers and other concerned bodies should give special attention to the implementation of effective tutorial class support for female students.
\end{abstract}

Keywords: Academic achievement, effects, tutorial class, female students.

\footnotetext{
* ADDRESS FOR CORRESPONDENCE: Sewagegn Mola Melaku, Department of Social Psychology, Wachemo University, Hosaena, Ethiopia.
} 


\section{Introduction}

Education in its general sense is a form of learning in which the knowledge, skills, values, beliefs and habits of a group of people are transferred from one generation to the next generation through discussion, teaching or research (Yeung et al., 2013). From the psychological point of view, education implies that change and can be regarded as a 'process' or 'product' (Crow, 2000). As a process, it embodies all those forms of activities that fit individuals for social living and that help to transmit activities, customs, laws, religious beliefs, languages and social intuitions from one generation to another. As a product, education includes all those changes that have taken place as a result of individuals participating in learning experiences (Crow, 2000).

The fact that learners differ in some particular aspects of important questions for educators and scientists, the youth differ greatly in their abilities, interest and motives and it is not an easy assignment to set up an educational programme that gives special attention to individual learners. These individual differences among pupils (students) in academic performance have been linked to the differences in intelligence personality. Students with higher mental ability have higher personality, especially conscientiousness (linked to the effort and achievement motivation), and tend to achieve high in the academic setting. There are inconclusive results over which individual factors successfully predict academic performance elements, such as test anxiety, environment, motivation and emotion, which require consideration when developing the models of school achievement (James, 2011). It is the function of the university to provide adequate programmes and schooling for every learner according to their individual differences due to either internal or external factors; no matter how much he/she deviates, teachers are responsible for the education of pupils and they must formulate their educational programmes with knowledge that the pupils should be offered and experience within the limits of individual ability (Crow, 2000).

Due to the pupil's or student's difference, tutorial class should be given special attention for female and low achiever students to increase their academic achievement (Coolidge \& Segal, 2004). Similarly, tutorial support plays an active role in increasing the academic achievement and performance of low achievers and female students. Students in all grade levels require tutorial support for the effectiveness of their teaching-learning system, especially for female students who have academic difficulties. Therefore, teachers are capable of meeting instructional needs of all students equally according to their individual differences, because students have unique intellectual capacities in the class to improve their academic performance (Paul \& Graham, 2002).

Academic achievement of students is the most important indicator of quality education in the country. So, academic achievement or academic performance is the extent to which students, teachers and institutions have achieved educational goals (Thomas et al., 2007). In different countries and at different times, various studies have been carried out to identify the effect of tutors who significantly influence students' academic achievement. The cognitive achievement of African students is low compared to the world standards and evidence points out the decline in recent years. Accordingly, the restoration and clarification of standards of academic performance are key to improving the qualities of education and producing qualified students who are advantageous for their country's development at all levels (Heiner, 2012; Gerhard, 2009; James, 2011).

Generally, tutoring plays a valuable role in helping one to improve the learning environment and navigate a stricter and uncertain regulatory landscape. Most importantly, it is fundamental to promoting a student success culture through improving the quality of staff-student relationships (Jayne \& Marsha, 2013). Therefore, there are different strategies to improve academic performance of female students. These are, first, knowing the abilities of students it is crucial because students are not homogenous; they have different needs, backgrounds and motivations for learning and different pressures. The recent work on student engagement and belonging is critical to understanding more about the profile of today's students (Thomas, 2017). Second, connecting students to their peers is an important method for improving students by encouraging peer networking and creating group-based 
learning opportunities to make tutorial class delivery easy (Herald et al., 2009). Third, good technologies will support considerably, with richer face-to-face interactions with students and devoting time early in the term to familiarising students with the guidelines for how tutorials will be run is the most important strategy to improve tutorial delivery for students (Thomas, 2017).

In Ethiopia, there are different levels of educational institutions, although most of the teachers and students have little awareness about the effectiveness and practice of tutorial delivery for female students. Similarly, a research conducted in Arba Minch and Mekelle Universities by Jara Elema shows that there is little awareness about the effectiveness and practice of tutorial delivery for female students. In addition, as one of the Ethiopian higher education institutions, Wachemo University is not engaged in effectiveness and practicing of tutorial delivery for female students due to teacher's and student's lack of awareness about the extent of tutorial support that is contributed towards students' academic performance. However, little emphasis seems to have been given to such issues that the problems are continuing and female students to such behaviours are left untreated. Therefore, the researcher tries to assess the effectiveness of the tutorial class for female students' academic achievement in Wachemo University College of Social Sciences and Humanities, which was guided by the following basic research questions:

1. What are the academic and psychological effects of tutorial classes on female students in Wachemo University College of Social Sciences and Humanities?

2. What is the interest of female students towards tutorial classes in Wachemo University College of Social Sciences and Humanities?

3. What are the strategies to improve the tutorial given to female students in Wachemo University College of Social Sciences and Humanities?

The general objectives of this study were to assess the effectiveness of tutorial classes on female students' academic achievement in Wachemo University.

\section{Methods and material}

By considering the nature of basic research questions and purpose of the study, as well as the expected research activities, the researcher used the experimental research design. The study aimed to establish possible causal relationships, to manipulate various levels of variables (independent variables, i.e., tutorial class) and to examine the effects on one or more outcome variables (dependent variables, i.e., academic achievements) while attempting to examine the effects of all other possible causal variables usually by holding them constant.

\subsection{Study groups}

The target population of the study was 598 female students and 114 (10 females and 104 males) teachers in Wachemo University College of Social Sciences and Humanities. The study was conducted in Hosanna town which is found in a southern regional state located approximately $230 \mathrm{~km}$ from the capital of Addis Ababa.

\subsection{Sample size and sampling techniques}

In Wachemo University, there are seven colleges. Among those colleges, social sciences and humanities was selected due to the researcher's familiarity with its departments and the problem's relevant to it. In Wachemo University, in the social sciences and humanities college, there were 598 female students and 114 teachers. Thus, the population for this quantitative study was the whole college of social sciences and humanities female students in Wachemo University. From this total population, $10 \%(60)$ of the total 598 female students were selected as sample members by a simple 
random sampling technique known as the lottery method to give equal chances for all female students. The researcher used Yemane's (1967) formula to select $10 \%$ of the female students.

$n=$ the required sample for the study;

$N=$ the total population of the interest for this study;

$P=$ the percentage taken.

$$
\begin{gathered}
\text { Sample }(n)=\frac{N \times P}{100} \\
(n)=\frac{598 \times 10}{100}
\end{gathered}
$$

$(n)=59.9 \sim 60$ (sample from total female students of Wachemo University College of Social Sciences and Humanities from all departments). From 114 teachers, 11 teachers were selected by a purposive sampling technique to get adequate knowledge about the study. Therefore, to meet this objective, 60 students and 11 teachers were selected as sample participants of the study.

\subsection{Data sources and types}

In this study, primary data was used to generate and extract all necessary information for the research. Both quantitative and qualitative approaches were used. While quantitative approach was employed to explain the numerical phenomena of the study, qualitative approach was employed to assess the attitude and opinion of the participants about the effectiveness of tutorial class for female students' academic achievement

\subsubsection{Data collection tools}

The instruments used for the study were primary data such as questionnaire and focus group discussion.

\subsubsection{Questionnaire.}

A self-administered questionnaire was the major instrument that was used in data collection. The researcher designed the questionnaires by reviewing the literature. The questionnaire consisted of closed and open-ended items to generate data about effectiveness of tutorial class for female student's their academic achievement. The questionnaires were administered for 60 students and 11 teachers in Wachemo University.

\subsubsection{Focus group discussions.}

Qualitative data were collected with the help of the focus group discussion. The researcher posed a set group interactive session within a small group for everyone to have a chance to talk and to get enough opinions about the tutorial class for female students on their academic performance.

\subsubsection{Data collection procedure}

After the questionnaire was developed and made ready for administration, a letter of cooperation from the Psychology Department was presented to concerned bodies of the study site (Wachemo University). Following this, the researcher explains the objective of the study to the students. Thereafter, the researcher secured the consent and collaboration of the participants, which is crucial for the success of the study. Subsequently, the researcher contracted one assistant who had a first degree in psychology for collecting data and gave a short orientation on how to do the task. Thereafter, the researcher explained the purpose of the study to the participants and asked their consent. The researcher administered the instrument to the participants. Then, the participants filled the questionnaire and returned the edited copy to the researcher and his assistants directly. The researcher collected the questionnaire after the completion of the survey. The return rate was $100 \%$. Finally, the participants were thanked for their cooperation. 


\subsubsection{Method of data analysis}

Finally, the data collected through the questionnaire and focus group discussion were analysed through quantitative and qualitative methods. The data obtained from questionnaires were analysed by using percentage, frequency and tables. The data obtained from the focus group discussion was analysed by using qualitative methods in thematic analysis of the data systematically.

\section{Results}

The analysis and interpretation of data collected from the respondents (i.e., students and teachers in Wachemo University College of Social Sciences and Humanities) is presented below.

\subsection{Background information of the respondents}

Table 1. Background information of female students

\begin{tabular}{lccc}
\hline \multicolumn{1}{c}{ Variables } & Category & $\boldsymbol{F}$ & $\%$ \\
\hline Sex & Female & 60 & 100 \\
Age & $18-20$ & 12 & 20 \\
& $21-24$ & 48 & 80 \\
Academic year & First year & 18 & 30 \\
& Second year & 21 & 35 \\
& Third year & 21 & 35 \\
Departments & Civics & 10 & 16.68 \\
& English & 7 & 11.67 \\
& Geography & 8 & 13.3 \\
& Hadiyisa & 10 & 16.68 \\
& History & 6 & 10 \\
& Psychology & 9 & 15 \\
& Sociology & 10 & 16.68 \\
\hline
\end{tabular}

Source: Own survey, 2019.

Table 1 shows that $60(100 \%)$ of the respondents were female students. From all, $12(20 \%)$ were in the 18-20 age group and $48(80 \%)$ were in the 21-25 age group; and 18 (30\%) were first-year, 21 (35\%) were second-year and 21 (35\%) of the respondents were third-year female students. From the total respondents, 10 (16.68\%) were from the civics department, 7 (11.67\%) were from the English department, 8 (13.3\%) were from the geography department, $10(16.68 \%)$ were from the Hadiyisa department, 6 (10\%) were from the History department, $9(15 \%)$ were from the psychology department and $10(16.68 \%)$ were from the sociology department.

Table 2 indicates that out of the total respondents $5(45.5 \%)$ were female and $6(54.5 \%)$ were were male; and 2 (18.2\%) were in the 20-25 age group, 7 (63.6\%) were in the 26-30 age group and 2 (18.2\%) were in the 31 and above age group. All respondents have an MA and above educational level. From the total respondents, 1 (9.1\%) was from civics, 2 (18.2\%) were from English, 1 (9.1\%) was from Geography, 2 (18.2\%) were from Hadiyissa, 2 (18.2\%) were from History, 1 (9.1\%) was from Sociology and $1(18.2 \%)$ was from the psychology department. 
Table 2. Background information of teachers

\begin{tabular}{lccc}
\hline \multicolumn{1}{c}{ Variables } & Categories & $\boldsymbol{F}$ & $\boldsymbol{\%}$ \\
\hline Sex & Male & 6 & 54.5 \\
Age & Female & 5 & 45.5 \\
& $20-25$ & 2 & 18.2 \\
Educational level & $26-30$ & 7 & 63.6 \\
& 31 and above & 2 & 18.2 \\
Department & Degree & - & - \\
& MA and above & 11 & 100 \\
& Civics & 1 & 9.1 \\
& English & 2 & 18.2 \\
& Geography & 1 & 9.1 \\
& Hadiyissa & 2 & 18.2 \\
& History & 2 & 18.2 \\
& Psychology & 2 & 18.2 \\
& Sociology & 1 & 9.1 \\
\hline
\end{tabular}

Source: Own survey, 2019.

\subsection{Academic effects of tutorial class}

Table 3. Respondents' response on academic achievement

\begin{tabular}{|c|c|c|c|c|c|c|c|c|c|c|c|c|c|}
\hline \multirow[t]{3}{*}{ No. } & \multirow[t]{3}{*}{ Items } & \multicolumn{10}{|c|}{ Responses } & \multirow{2}{*}{\multicolumn{2}{|c|}{ Total }} \\
\hline & & \multicolumn{2}{|c|}{$\begin{array}{l}\text { Strongly } \\
\text { agree }\end{array}$} & \multicolumn{2}{|c|}{ Agree } & \multicolumn{2}{|c|}{ Undecided } & \multicolumn{2}{|c|}{ Disagree } & \multicolumn{2}{|c|}{$\begin{array}{l}\text { Strongly } \\
\text { disagree }\end{array}$} & & \\
\hline & & $F$ & $\%$ & $\boldsymbol{F}$ & $\%$ & $F$ & $\%$ & $\boldsymbol{F}$ & $\%$ & $F$ & $\%$ & $F$ & $\%$ \\
\hline 1 & $\begin{array}{l}\text { After I receive tutorial, my } \\
\text { participation is better than } \\
\text { before }\end{array}$ & 32 & 53.4 & 17 & 28.3 & 6 & 10 & 2 & 3.3 & 3 & 5 & 60 & 100 \\
\hline 2 & $\begin{array}{l}\text { I scored poor before taking } \\
\text { tutorial education }\end{array}$ & 26 & 43.4 & 22 & 36.7 & 5 & 8.3 & 4 & 6.6 & 3 & 5 & 60 & 100 \\
\hline 3 & $\begin{array}{l}\text { I do not think that the } \\
\text { tutorial support has } \\
\text { contributed to my academic } \\
\text { performance }\end{array}$ & 1 & 1.7 & 3 & 5 & 5 & 8.3 & 29 & 48.3 & 22 & 36.7 & 60 & 100 \\
\hline 4 & $\begin{array}{l}\text { Attending tutorial improve } \\
\text { my grade point average }\end{array}$ & 34 & 56.7 & 18 & 30 & 4 & 6.7 & 2 & 3.3 & 2 & 3.3 & 60 & 100 \\
\hline 5 & $\begin{array}{l}\text { I think that, tutorial support } \\
\text { has contributed to my } \\
\text { improved performance }\end{array}$ & 30 & 50 & 22 & 36.7 & 3 & 5 & 3 & 5 & 2 & 3.3 & 60 & 100 \\
\hline
\end{tabular}

Source: Own survey, 2019.

The purpose of the study was to assess the effectiveness of tutorial classes for female students on their academic achievement in Wachemo University College of Social Sciences and Humanities. Table 3 shows that majority of the respondents $(32,53.4 \%)$ strongly agreed and $2(3.3 \%)$ disagreed that after they received tutorial class their participation in class was better than before. Therefore, the results revealed that receiving tutorial class improves female students' participation in the class. Out of the total respondents, $26(43.4 \%)$ strongly agreed and $3(5 \%)$ disagreed on before taking tutorial class they were scored poorly. So, the results revealed that most female students scored poorly before taking tutorial class. 
Out of the total respondents $1(1.7 \%)$ agreed and 29 (48.3\%) strongly disagreed that they do not think that tutorial support had contributed to their academic performance. Therefore, the results revealed that few of the respondents do not think that tutorial support had contributed to their academic performance in the class. Out of the total respondents, 34 (56.7\%) agreed and 2 (3.3\%) disagreed on attending tutorial class to improve their grade point average. Therefore, the results revealed that attending tutorial class improved female students' grade point average and $30(50 \%)$ of the respondents strongly agreed and $2(3.3 \%)$ strongly disagreed that they think that tutorial support had contributed to their improved performance. Therefore, the results revealed that most of the female students think tutorial support had contributed to their improved academic performance.

\subsection{Psychological effects of tutorial class}

Table 4. Respondent's psychological effect of tutorial class

\begin{tabular}{|c|c|c|c|c|c|c|c|c|c|c|c|c|c|}
\hline \multirow[t]{3}{*}{ No } & \multirow[t]{3}{*}{ Items } & \multicolumn{12}{|c|}{ Responses } \\
\hline & & \multicolumn{2}{|c|}{$\begin{array}{l}\text { Strongly } \\
\text { agree }\end{array}$} & \multicolumn{2}{|c|}{ Agree } & \multicolumn{2}{|c|}{ Undecided } & \multicolumn{2}{|c|}{ Disagree } & \multicolumn{2}{|c|}{$\begin{array}{l}\text { Strongly } \\
\text { disagree }\end{array}$} & \multicolumn{2}{|c|}{ Total } \\
\hline & & $\boldsymbol{F}$ & $\%$ & $\boldsymbol{F}$ & $\%$ & $F$ & $\%$ & $\boldsymbol{F}$ & $\%$ & $F$ & $\%$ & $\boldsymbol{F}$ & $\%$ \\
\hline 1 & $\begin{array}{l}\text { After I receive tutorial } \\
\text { class, my decision- } \\
\text { making skill was } \\
\text { developed }\end{array}$ & 23 & 38.33 & 26 & 43.33 & 5 & 8.3 & 4 & 6.68 & 2 & 3.3 & 60 & 100 \\
\hline 2 & $\begin{array}{l}\text { When I evaluate my } \\
\text { confidence since when } \\
\text { I was started tutorial, } \\
\text { my confidence changed } \\
\text { or improved }\end{array}$ & 21 & 35 & 29 & 48.4 & 3 & 5 & 2 & 3.3 & 5 & 8.3 & 60 & 100 \\
\hline 3 & $\begin{array}{l}\text { After I receive the } \\
\text { tutorial class, my self- } \\
\text { concept increases }\end{array}$ & 19 & 31.7 & 36 & 60 & 2 & 3.3 & 1 & 1.7 & 2 & 3.3 & 60 & 100 \\
\hline 4 & $\begin{array}{l}\text { After I receive tutorial } \\
\text { class, I feel happy }\end{array}$ & 33 & 55 & 17 & 28.3 & 4 & 6.7 & 1 & 1.7 & 5 & 8.3 & 60 & 100 \\
\hline 5 & $\begin{array}{l}\text { After I receive tutorial, } \\
\text { my memory was } \\
\text { increased }\end{array}$ & 18 & 30 & 32 & 53.3 & 3 & 5 & 4 & 6.7 & 3 & 5 & 60 & 100 \\
\hline
\end{tabular}

Source: Own survey, 2019.

The purpose of the study was to assess the psychological effect of tutorial class on female students in Wachemo University College of Social Sciences and Humanities. Table 4 shows that 26 (43.33\%) respondents agreed and $2(3.3 \%)$ strongly disagreed that when they received tutorial class their decision-making skill was developed. So, the results revealed that receiving tutorial class improves the decision-making skill of female students. Out of the total respondents, 21 (35\%) strongly agreed and 5 (8.3\%) strongly disagreed that when they started tutorial classes their self-confidence was changed or improved. Therefore, the results revealed that receiving tutorial class had a positive psychological effect on female students' self-confidence development.

With regard to after receiving tutorial class their self-concept was increased, 36 (60\%) agreed and 2 (3.3\%) strongly disagreed. Therefore, the results revealed that receiving tutorial class increased female student's self-concept. Again, 33 (55\%) strongly agreed and 5 (8.3\%) strongly disagreed on when they received tutorial class they felt happy. Therefore, the results revealed that most female students were happy after they received tutorial class. Also, 32 (53.3\%) agreed and $3(5 \%)$ strongly agreed that after they received a tutorial, their memory had increased. Therefore, the results revealed that receiving tutorial class improves a female student's memory capacity. 
Table 5. Respondents' interest towards tutorial class

\begin{tabular}{|c|c|c|c|c|c|c|c|c|c|c|c|c|c|}
\hline \multirow[t]{3}{*}{ No } & \multirow[t]{3}{*}{ Items } & \multicolumn{12}{|c|}{ Responses } \\
\hline & & \multicolumn{2}{|c|}{$\begin{array}{l}\text { Strongly } \\
\text { agree }\end{array}$} & \multicolumn{2}{|c|}{ Agree } & \multicolumn{2}{|c|}{ Undecided } & \multicolumn{2}{|c|}{ Disagree } & \multicolumn{2}{|c|}{$\begin{array}{l}\text { Strongly } \\
\text { disagree }\end{array}$} & \multicolumn{2}{|c|}{ Total } \\
\hline & & $F$ & $\%$ & $F$ & $\%$ & $\boldsymbol{F}$ & $\%$ & $F$ & $\%$ & $F$ & $\%$ & $F$ & $\%$ \\
\hline 1 & $\begin{array}{l}\text { I receive tutorial } \\
\text { voluntary }\end{array}$ & 23 & 38.3 & 32 & 53.3 & 2 & 3.3 & 2 & 3.3 & 1 & 1.7 & 60 & 100 \\
\hline 2 & $\begin{array}{l}\text { I am interested on my } \\
\text { tutorial classes }\end{array}$ & 27 & 45 & 24 & 40 & 5 & 8.3 & 1 & 1.7 & 3 & 5 & 60 & 100 \\
\hline 3 & $\begin{array}{l}\text { I am punctual on my } \\
\text { tutorial class }\end{array}$ & 35 & 58.3 & 14 & 23.3 & 4 & 6.7 & 3 & 5 & 4 & 6.7 & 60 & 100 \\
\hline
\end{tabular}

Source: Own survey, 2019.

The purpose of the study was to assess female students' interest towards tutorial class in Wachemo University College of Social Sciences and Humanities. Table 5 indicates that 23 (38.3\%) strongly agreed and $1(1.7 \%)$ strongly disagreed that they received tutorial support voluntarily. So, the results revealed that majority of the female students received tutorial class voluntarily. Also, 27 (45\%) strongly agreed and $3(5 \%)$ o strongly disagreed that they were interested towards their tutorial classes. Therefore, the results revealed that female students were interested towards their tutorial classes. Regarding their punctuality on their tutorial classes, 35 (58.3\%) respondents strongly agreed and $4(6.7 \%)$ strongly disagreed that they were punctual on their tutorial. So, the results revealed that female students were punctual or being on time in their tutorial classes.

\subsection{Respondents' test performance in the class}

The purpose of the study was to assess test performance of female students in the class in Wachemo University College of Social Sciences and Humanities.

Table 6. Respondents' test performance

\begin{tabular}{lcccc}
\hline \multicolumn{2}{c}{ Range of score } & Before receiving tutorial & \multicolumn{3}{c}{ After receiving tutorial } \\
& $\boldsymbol{F}$ & $\boldsymbol{\%}$ & $\boldsymbol{F}$ & $\%$ \\
\hline Below 5 & 9 & 15 & 3 & 5 \\
$5-7$ & 5 & 8.3 & 9 & 15 \\
$7.5-10$ & 4 & 6.7 & 6 & 10 \\
\hline
\end{tabular}

Source: Own survey, 2019.

Table 6 indicated that 18 (30\%) respondents took the tests before and after receiving tutorial class. Before receiving the tutorial, majority of the respondents scored below 5 points. On the other hand, after receiving the tutorial, majority of the respondents scored above 5 points. The results indicated that their test performance was increased after they received tutorial class. Therefore, tutorial class is an effective way of improving female students' academic achievement and performance. Similarly, evaluating the effectiveness of tutorial support motivates and encourages female students and teachers towards better academic performances of female students.

\section{Discussion}

In this section, the findings of the present investigation were discussed in light of the findings of previous studies and possible explanations on the effectiveness of tutorial class for female student's academic achievement.

One of the objectives of the present study was to assess the academic and psychological effects of tutorial class for female students in Wachemo University College of Social Sciences and Humanities. To do this, percentages, tables and frequencies were employed in the form of questionnaire and focus 
group discussion. Therefore, the results revealed that tutorial support has both academic and psychological effects for female students. Academically, tutorial class is effective in improving students' academic performance and class participation. Psychologically, tutorial support is effective in improving their self-confidence, self-concept, decision-making ability, memory (remembering ability) and feeling of happiness. Previous findings have indicated that tutorial classes positively affect academic performance of female students (Peter et al., 1982).

The other objectives of the present study were to assess female students' interest towards tutorial class in Wachemo University College of Social Sciences and Humanities. To do this, percentages, tables and frequencies were employed in the form of questionnaire and focus group discussion. Therefore, the results revealed that high tutorial class interest directly influences female students' academic performance and achievements. Previous findings indicated that tutoring may be particularly helpful in improving the classroom performance of learners who received tutoring class that assist them with daily assignments and help them to develop efficient organisational and study skills (Rani \& David, 1998). Similarly, tutoring plays a valuable role in helping one to improve the learning environment and to navigate a stricter and uncertain regulatory landscape. Most importantly, it is fundamental to promoting a student success culture through improving the quality of staff-student relationships (Jayne, Peggy \& Marsha, 2013).

One of the objectives of the present study was to assess the strategies to improve tutorial given to female students in Wachemo University College of Social Sciences and Humanities. To do this, thematic analysis was employed in the form of focus group discussion. Therefore, the results revealed that there are strategies to improve tutorial delivery for female students. These strategies are the abilities of students, connecting students with their peers, setting tutorial learning goals, preparing supporting materials, acting in a professional manner, motivating and encouraging females to improve their academic performance. Previous findings indicated that knowing the abilities of students it is crucial because students are not homogenous; they have different needs, backgrounds and motivations for learning and different pressures. Recent work on student engagement and belonging is critical to understand more about the profile of today's students (Thomas, 2017). Second, connecting students to their peers this is an important method to improve students by encouraging peer networking and creating group-based learning opportunities to make tutorial class delivery easy (Herald et al., 2009). Third, good technologies will support considerably, with richer face-to-face interactions with students and devoting the time early in the term to familiarising students with the guidelines for how tutorials will be run is the most important strategy to improve tutorial delivery for students (Thomas, 2017).

\section{Conclusion}

Depending on the findings on the study, the following concluding remarks were made:

- Tutorial support has both academic and psychological effects on female students. Academically, tutorial class is effective improving a student's grade point average and academic performance and class participation. Psychologically, tutorial support is effective in improving their self-confidence, self-concept, decision-making ability, memory (remembering ability) and feeling of happiness.

- Female students in Wachemo University College of Social Sciences and Humanities have a positive interest towards their tutorial classes. Therefore, they are being punctual to receive tutorial classes voluntarily.

- There are so many strategies to improve tutorial delivery for female students. These strategies are the abilities of students, connecting students with their peers, setting tutorial learning goals, preparing supporting materials, acting in a professional manner, motivating and encouraging females to improve their academic performance. 


\section{Recommendations}

Keeping in mind that the findings of the study, the following suggestions are recommended:

- Tutorial support is an indispensable factor in the achievement of educational goals and objectives. So, students, teachers and concerned bodies have a tutorial class to enhance teaching and learning systems in the institution.

- Female student's tutorial support service should be framed and focused to improve their academic performance. So, teachers and other concerned bodies design different mechanisms and strategies to make tutorial support adaptable in the institution.

- Teachers should be encouraged and fully committed to providing effective professional support for their students in tutorial classes by working together with professional colleagues for further academic improvement (achievement) of female students.

- The university should give special attention to the implementation of effective tutorial class support and design new strategies for tutorial delivery to bring about the awareness of the importance of effective tutorial support for female students.

- Also, the university should facilitate, encourage and motivate teachers and senior students (especially graduate students) about the effectiveness of tutorial support on female students' academic achievement.

\section{Acknowledgments}

It gives them great respect to thank all the study participants for their cooperation in providing the necessary information. The authors are grateful to the research assistants who participated in data collection and supervision in this study. Finally, the authors greatly thank Wachemo University and the Psychology Department.

\section{References}

Bossert, T. J., Bossert, T., Barnighausen, T., Bowser, D., Mitchell, A. \& Gedik, G. (2007). Assessing financing, education, management and policy context for strategic planning of human resources for health. Geneva, Switzerland: World Health Organization. Retrieved from https://apps.who.int/iris/handle/10665/43780

Ladd, G. W., Herald-Brown, S. L. \& Kochel, K. P. (2009). Peers and motivation. Educational psychology handbook series. Handbook of motivation at school (pp. 323-348). Oxfordshire, UK: Routledge/Taylor \& Francis Group.

Cohen, P. A., Kulik, J. A. \& Kulik, C. L. C. (1982). Educational outcomes of tutoring: a meta-analysis of findings. American Educational Research Journal, 19(2), 237-248. Retrieved from http://www.jstor.org/stable/ 1162567

Coolidge, F. L. \& Segal, D. L. (2004). Objective assessment of personality and psychopathology: an overview. Comprehensive handbook of psychological assessment (vol. 2, pp. 3-13). Hoboken, NJ: John Wiley \& Sons Inc.

Cooper, P., Smith, C. J. \& Upton, G. (2002). Emotional and behavioural difficulties: theory to practice. Emotional and behavioural difficulties: Theory to practice (1st ed.).Oxfordshire, UK: Routledge.

Crow, D. (2000). Educational psychology textbook binding (2nd ed.). Ney York, NY: Van Nostrand Reinhold.

Drake, J. K., Jordan, P. \& Miller, M. A. (2013). Academic advising approaches: strategies that teach students to make the most of college. Hoboken, NJ: John Wiley \& Sons Inc.

George, R. \& Kaplan, D. (1998). A structural model of parent and teacher influences on science attitudes of eighth graders: evidence from Nels: 88. Science Education, 82(1), 93-109.

Law, N. W. Y., Yuen, J. K. L. \& Lee, Y. (2013). E-learning pedagogy and school leadership practices to improve Hong Kong Students' Computer and Information Literacy: findings from ICILS and beyond. Centre for 
Information technology in education (CITE), Faculty of Education, The University of Hong Kong. Retrieved from http://hdl.handle.net/10722/230426

Meisenberg, G. (2009). Designer babies on tap? Medical students' attitudes to pre-implantation genetic screening. Public Understanding of Science, 18(2), 149-66.doi:10.1177/0963662507079374

Rindermann, H. (2012). African cognitive ability: research, results, divergences and recommendations. Personality and Individual Differences, 55(3), 229-233. Retrieved from www.elsevier.com/locate/

Thomas, G. (2017). How to do your research project: a guide for students. Thousand Oaks, California: Sage Publisher. Retrieved from https://books.google.com.et/books?id=ZqzDDgAAQBAJ

Thompson, S. (2011). Reading achievement of U.S. fourth-grade students in an International context. National Centre for Education Statistics, Institute of Education Sciences, U.S. Department of Education. Washington, DC: Government Printing Office.

Yemane, T. (1967). Elementary sampling theory. Hoboken, NJ: Prentice-Hall. 